Témoigner Témoigner. Entre histoire et mémoire

Getuigen Revue pluridisciplinaire de la Fondation Auschwitz

$123 \mid 2016$

Traduire le témoignage

\title{
Guy Cassiers en Erwin Jans, De Welwillenden
}

Les Bienveillantes

\section{Anneleen Spiessens}

\section{(2) OpenEdition}

\section{Journals}

Édition électronique

URL : https://journals.openedition.org/temoigner/5074

DOI : $10.4000 /$ temoigner. 5074

ISSN : 2506-6390

Éditeur :

Éditions du Centre d'études et de documentation Mémoire d'Auschwitz, Éditions Kimé

Édition imprimée

Date de publication : 1 octobre 2016

Pagination : 13-17

ISBN : 987 2-9600926-4-6

ISSN : 2031-4183

Référence électronique

Anneleen Spiessens, «Guy Cassiers en Erwin Jans, De Welwillenden», Témoigner. Entre histoire et mémoire [Online], 123 | 2016, Online op 02 novembre 2021, geraadpleegd op 04 novembre 2021. URL: http://journals.openedition.org/temoigner/5074 ; DOI: https://doi.org/10.4000/temoigner.5074 


\section{DE WELWILLENDEN}

THEATER "Laat me u vertellen hoe het ging. Het is een trieste geschiedenis, maar toch ook een verhaal met een moraal. Een vrij lang verhaal, er heeft zich heel wat afgespeeld. Maar misschien bent $u$ niet gehaast, misschien heeft $u$ tijd. Ik zal er alles aan doen om duidelijk te blijven. $U$ hebt de garantie dat in wat ik u ga vertellen geen enkele wroeging zal doorklinken. Ik heb nergens spijt van, ik deed mijn werk, meer niet."

\section{Aan het woord is Max Aue, gespeeld door de Nederlandse acteur Hans Kesting. Als oude man blikt hij terug op zijn carrière bij de SD, later de SS, waar hij in het spoor van de Duitse Einsatzgruppen de 'Holocaust door kogels' aan het oostfront mee overzag en na een passage in Stalingrad naar Berlijn werd afgevaardigd om de inzet van gevangengenomen Joden in de oorlogseconomie te bestuderen. Vanop de bühne spreekt hij zijn publiek nu rechtstreeks toe.}

$\mathrm{T}$ oen de onbekende Amerikaanse schrijver Jonathan Littell in 2006 Les Bienveillantes (De Welwillenden) uitbracht, werd de roman een instantbestseller in Frankrijk. Het boek won zowel de Prix Goncourt als de Prix de l'Académie française, en werd in meer dan vijftien talen vertaald. Tezelfdertijd werd het verguisd door een deel van de Franse (en ook Amerikaanse) literaire kritiek. Een onwaarschijnlijke en onfatsoenlijke mengeling van fictie en geschiedenis, zo werd beweerd, maar het was voornamelijk het vertelperspectief van de nazibeul dat een aantal critici tegen de borst stuitte. ${ }^{1}$ Laat het nu net op die twee niveaus zijn - de rol van fictie en het standpunt van de dader - dat regisseur Guy Cassiers en dramaturg Erwin Jans een punt willen maken in hun toneelbewerking van de roman.

\section{VERBEELDING EN DE HOLOCAUST}

De scène is minimalistisch: geen swastika's, geen SS-uniformen, geen rode vlaggen maar een kale ruimte metroestige opeengestapelde archiefkasten. Hetdecor is geïnspireerd op de installaties van de Franse kunstenaar Christian Boltanski: opgebouwd rond oude documenten, verzamelingen en archieven, vormen ze elementen in de strijd tegen het vergeten. Voor de kunstenaar is die strijd persoonlijk: Boltanski is geboren op de dag dat Parijs werd bevrijd en behoort dus tot de 'postmemoriale' generatie (Hirsch 1996, 675) zonder eigen herin- neringen aan de Holocaust. 'My work is not about, it is after', bevestigt hij in een interview met Georgia Marsh (Marsh 1990,10). Het is daarom via 'Holocausteffecten' (van Alphen 2007,368) - aan de hand van symbolische, niet-letterlijke referenties - dat hij de gebeurtenissen uit het verleden oproept, en daarmee juist de idee van afstand, afwezigheid en verlies. Ook de archiefkasten op het toneel verwijzen dus slechts impliciet naar de Holocaust en zijn in eerste instantie een grote metafoor voor de (ontbrekende) herinnering. In het eerste deel van het stuk zijn de kasten gesloten, maar naar het einde toe lijken ze een eigen leven te gaan leiden: een na een slaan de deurtjes vanzelfopen, waardoor het archief een soort van monster lijkt te worden. 'Ineens voel ik de volle last van het verleden,' stelt Aue vast, 'van de pijn die hoort bij het leven en bij de onontkoombare herinnering.'

De archiefkasten symboliseren echter niet alleen de collectieve en persoonlijke herinnering; ze verwijzen ook naar de specifieke methode die de Holocaust typeerde. Inventariseren en catalogiseren tot in het

(1) Het was nochtans niet de eerste keer dat een fictieve nazibeul het woord nam in een Franstalige roman. Dat gebeurde eerder onder andere al in L'Enfance d'un chef (Sartre 1939), Le Roi des Aulnes (Tournier 1970) en Le Bonheur nazi (Rachline 1972). In andere taalgebieden verschenen teksten met een gelijkaardig vertelperspectief: Deutsches Requiem (Borges 1946), The Man in the High Castle (Dick 1962), ), Le Nazi et le barbier (Hilsenrath 1971), The Iron Dream (Spinrad 1972), Siegfried (Mulisch 2001) of The Castle in the Forest (Mailer 2007). Voor een uitgebreidere studie van het daderperspectief verwijs ik naar Mingelgrün (2009) en Spiessens (2016). 


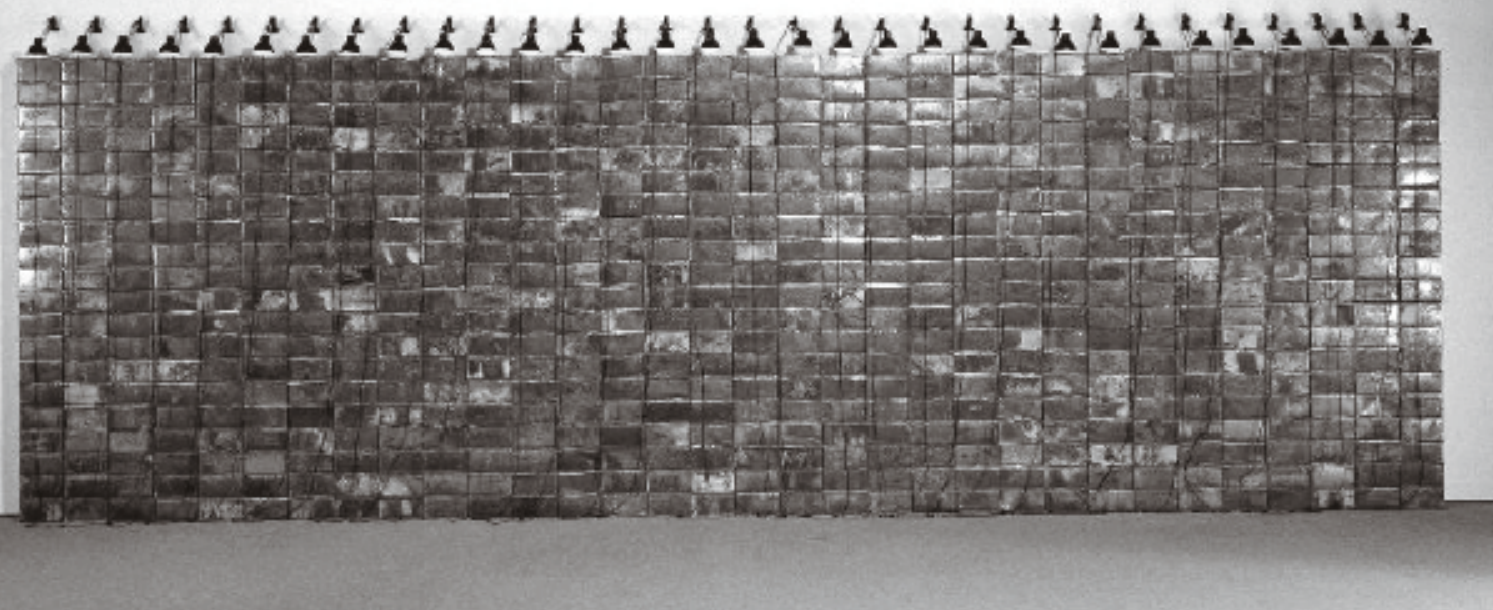

- Les Archives de C.B. Installatie van 646 koekjesdozen die zo'n 1200 foto's en 800 andere documenten bevatten
Christian Boltanski, 1965-1988

- extreme dat was wat de nazi's deden met hun slachtoffers: ze ontnamen hun elke vorm van individualiteit en maakten er archiveerbare objecten van. In het tweede deel van het theaterstuk worden de archiefkasten op het podium gerecupereerd door Eichmann - in het spe tisch figuur. Ze vormen letterlijk en figuurlijk de achtisch figun. Ze vormen letterlijk en figuurlijk de achtergrond van een aante duste discus fiches. Want hoe bereken je de capaciteit var jes en

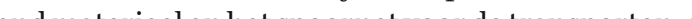
end materieel en het spoornet voor de transporten, en werion periode te laten sterven'?

Boltanski's archieven, en daarmee ook Cassiers ecor, vormen duidelijk een kritiek op de dominante 'realistische' en puur historische manier van represenfens

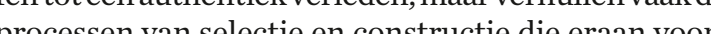
processen van selectie en constructie die eraan voorafgaan. Het is Boltansk's achterdocht tegenover het che vertelt, entegenover de intellectuele mechanismenvan lagen van de genocide, die zijn werk fundame basis agen van de genocide, die zijn werk fundamentee ironisch maakt (vgl. Bergman-Carton 2001). Met zijn opvan fictie in ditgeval theater om het delicate onder- werp van de judeocide te behandelen volgens haar eigen rocedés en via haar eigen beeldtaal. Het is immers via pe motionele lading kunnen geven en de toeschouwe mental dichterbij de realiteit brengen (Perrot \& Cassiers 2015, 61-63).

Cassiers en Jans houdt overduielijk een reflectie in op de kracht en tegelijkertijd de digvoortdur beelden. Tkhebhet idee dat we tegenwoorgroortdur

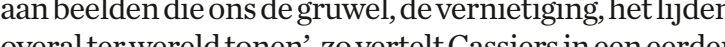
' interview met Getuigen, maar dat is het probleem met (Perrot 8 Cars 2015,60 ) Op het tre je eraan went, (Pijkt hij Cassirs 2015, 60) Op het treinspoor na ontwe associer verwijzing ve tie en poêzie. De massaslachting bij Babi Jar, waar de twee dagen tijd, wordt uitgebeeld aan de hand van ee inee dagen tijd, wordt uitgebeeld aan de hand van een intallatie de denke aan het werk van de Japanse Chiharu Shiota: een hoop schoenen, opgehangen boven het podium aan lange, dikke, rode veters. Elk van die schoenen stelt de afwezigheid voor van het lichaam van zijn eigenaar, en ling van extreem geweld mag dan een uiterst delicate kwestie zijn waarop vele taboes rusten (denk maar aan uitspraken van Claude Lanzmann in die richting; vg. (1) en theater in hetbit ethisch verantwoord kan zijn.

IK, DE NAZIBEUL

De naziofficier die Cassiers en acteur Hans Kesting creëren is geen psychopaat. Hij voelt een 'heftige drang naar het absolute en naar het overschrijden van grenzen', dat wel. Die zoektocht naar het avontuur en dic radicaal hij ineter dij heterste tafereelvan zijn oversten tehoren krijg den vermoord, slat bij hem de twiifel toe Achter die twijfel gat weliswar een ration ween Jodeen is nomelijk geen efficiënte oposs den van alle Joden is namelijk geen efficiènte oplossing voor het ' ichzelf wel degelijk als een 'fat', nlijk man' We zien hem later in esprek met de kleine Jakov, We zien jon jongetje dat Bach speelt op zijn viool en voor wie hij ('misschien wel het allermooiste wat er bestat'). De ('misschien wel het allernooiste wat er bestaat'). De ( entij

De meeste collega's van Aue zijn trouwens geen sadisten maargewonemannen, echtgenoten en vaders, dien 'Smeerlapperij, het is een grote smo die ze krijschre 'S schreeuwt de ene, terwijl de andere een kritisch betoo

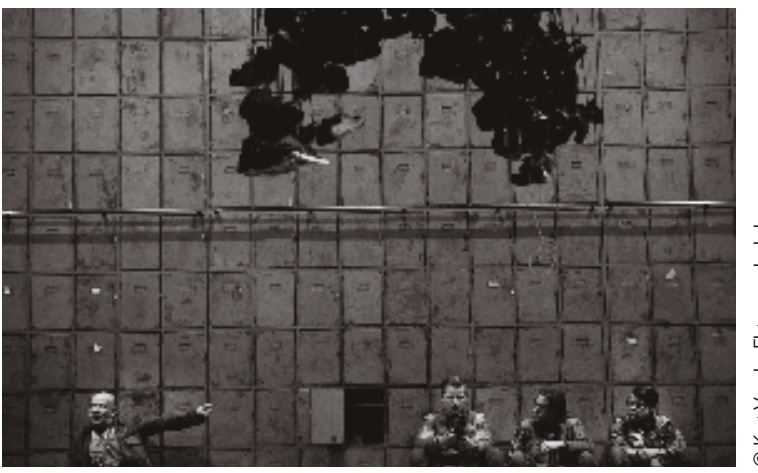

houdt tegen de pseudowetenschappelijke rassentherie van de nazi's. Nog een andere collega is bedroef ingenieur werd opgeleid om bruggen te 作 ch in ich in lijkt dich .

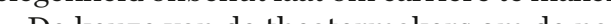

De keuze van de theatermakers om de nadruk te

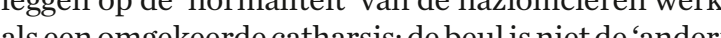
hij is is is precies de gelijkenis tussen de to chower hoer sen? En hoe zouden wij hebben ral geld, we ons in de situatie van Aue hebben bevo, we ons in de situatie wan Aue hebben bevonden? Een a zijn 'ikzen ne overkon net als u' eerder provocerend dan serieus voor zij bew ring Ieder van ons zou in bepunte oor zijn bewening. Ieder van ons zou in bepaalde de regisseur Het komt er dan op neer om de rismen 'gewone' mensen in die machine te onderzeken, 'gewone mensen in die machine te onderzoeken, een Harald Welzer al jaren bezighoudt (Browning 1992; Welar

De identificatie tussen toeschouwer en hoofdpersonage wordt in de hand gewerkt door de uitgekiende scenografie. Tijdens de inleiding, wanneer Aue het het ging', verbreekt Cospie bit on te tonelillusie. De lichten in de zal zijn nog niet volledig edoofd

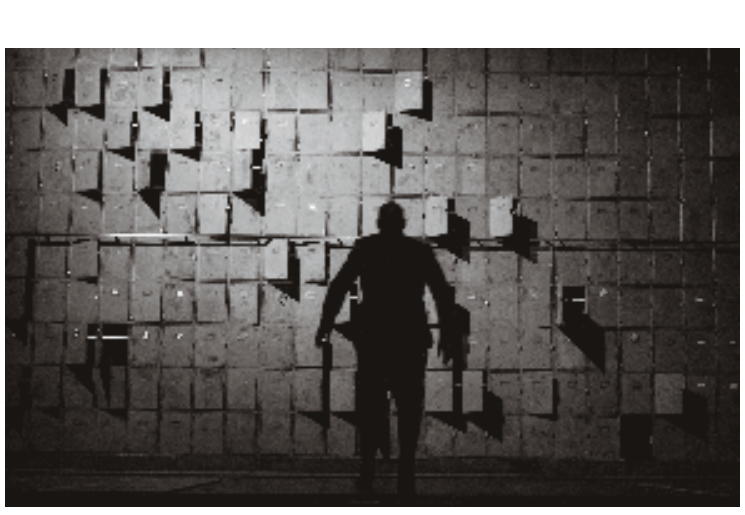


-. wanneer de Obersturmbannführer aan zijn monoloog begint. Dat gebeurt pas na Aues finale waarschuwing 'Het werkelijke gevaar voor de mens, dat ben ik, en dat u. u maar weggaan.' Kesting mag dan wel een acteur zij dieennomanpersuge incaneert, wat we zien is niet 'zonaar ton. vin de beter a van de beul en afien van een al te zelfgenoegzane demonis Aue de opdracht krijgt on de gewonden af te maken hetravijn van Babi Jar, worden we meegesleurd in zijn vesting dromentrons Kestingstaat vooran op het podium; achterhem hang een gaasdoekmet daarop een gigantische projectie van zijn hoord, icht vervor het ware in zijn geest. Het beeld wordt echter steed het relaas doet van zijn onrustige nacht.

Om deze oefening centraal te kunnen stellen in Om deze oefening centraal te kunnen stellen in het stuk, moest wel een bijzondere montage worden gemaakt van het tekst haterial. Daar waar Littell de Aues brein-deprerse distere achterkation Ans met zijn zus Una en de brute moorden die hij pleeg buiten zijn dienst - kijgen we in de theaterbewerking cen redelijk en voonk 'cen berput 'een beerput, een wurgend moeras. In tegenstelling tot enkele van zijn collega-officieren vraagt hij echte geen overplaatsing aan. Uit nieuwsgierigheid gaat hij vortdurend zichzelf en de imper o

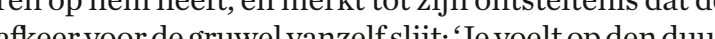
afkeer voor de gruwel vanzell slijt: Je voelt op den duu niet veel meer, je raakt er eigenlijk aan gewend. De aanbakles sch beklemmende opwinding, die steeds korter duurt, [... in de modder, terwijl ik zoek naar het licht'.

\section{DE TAAL VAN HET KWAAD}

De Welwillenden past binnen een ruimer project warin Cassicrsen Jans via theater het kwaad bestuderen als institutioneel, matschappelijk èn tallgmechanisme. Het mag dan ook niet verbazen dat de makers zorgden voor een uitgebreide historische context en theater het recht op fictie opeist bij de representatie

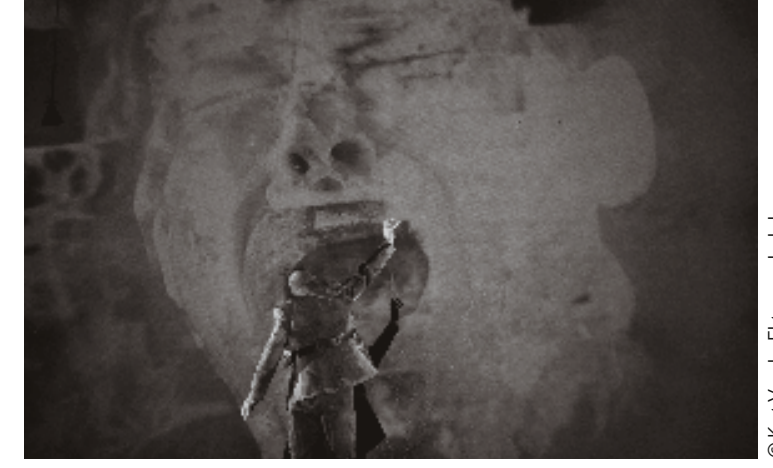

van de Holocaust, dat het geen geschiedkundige duiding behoeft. Integendeel: pas met een gedegen feitelijke kennis over het verleden is het mogelijk het puur documentaire niveau te overstijgen. Littell zelf werd trouwens geprezen om het minutieuze archiefonderDeek dat aan de basis lag van zijn roman

De teams van het Toneelhuis en Toneelgroep Amsterdam ontwikkelden Test of Civilisation, een online longread in vijf talen die een overzicht bied van de belangrijkste fases van de Jodenvervolging tiende- antisen tische gedoricus Hoed van de negentience schke over uitspraken van nazkopstukken als Hitler, tijdens zijn Menget tot deverdeding van Eichmann tijdens zijn proces in 1962. De nadruk ligt hier op het syma die de naz's inzetten om de ander de mechanismen die de nazi's inzetten om de ander de stigmatiseren.

In dit verband maakte Cassiers in 2015 al een voorstudie op basis van Le sec et l'humide, een essay waarin Jonathan Littell de stellingen van de Duitse socioloog Klaus Theleweit toetst aan het taalgebruik van de Belgische fascist Léon Degrelle. De relatie tussen mach en taal is immers een geliefkoosd thema bij Cassiers. tot in het absurde te rationli tot in het absuide te rationaliseren, zodat mensen hun gevoeligheid en hun verantwoordelijkheidsbesef verliezen en uiteindelijk 'het onverdedigbare [...] verdedigen "(Perrot \& Cassiers 2015, 62). In de toneelbe werking van De Welwillenden is het Thomas Hauser, consequenties van het nazi-jargon overdenkt:

Mensen geloven nog dat woorden ideeën aanduiden Maar volgens mij bestaan ideeën niet echt. Er zijn alleen maar woorden en het gewicht dat ze hebben. We heb- ben ons laten meeslepen door een woord [Endlösung] onontkoombaarheid ervan! Want het is toch onmogelijk om weerstand te bieden aan de verleidin van een dergelijk woord. Dat is even onvoorstelbaar a

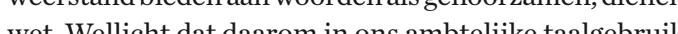

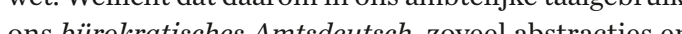
ons burrohratsches Amlsdentsch, zoveel abstracties en joden zijn vervoerd', ‘dezerware n: 'cr is bestoten', 'ce

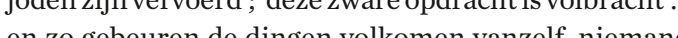

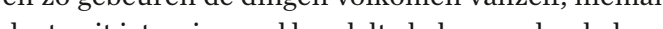

Het Duitse staatsapparaat had een taal uitgevonden die de dingen als onafwendbaar en noodzakelijk voorstelde en de slachtoffers als Untermenschen.

Het nazi-jargon als talig kluwen waarin gewone mensen verstrikt raken: daarin schuilt meteen het gevaar waarvoor Cassiers de toeschouwers ookvandaag wil behoeden, door hen te dwingen tot reflectie. In de will ongread Test of Civilisation legt dramaturg Erwin Jan verbanden tussen taalmechanismen in gewelddadige in Zuid-A rrika segres (Holocaust in Europa, apartheid in Zuid-Arika, segregatie in de VS) en nu (seksisme, racisme, hate speech, pesten). Ook de mediaverslaggeving over de huidige vluchtelingencrisis, net als de vluchtelingen op te vangen, walloper vluchtelingen op te vangen, wordt op de korrel genoEvian, in 1938 samengerepen doo co Amentie van brian, in 138 samengeroepen door de Amerikaanse president Roosevelt met de bedoeling een plan uit te werken onde massa Joodse vluchtelingen op te vangen die Duitsland moesten verlaten. Via het digitale platform Invisible Cities spoort de publiekswerking van het Toneelhuis laatstejaarsstudenten journalistiek van deAP Hogeschool Antwerpen bovendien aan om de problematiek van uitsluiting op microniveau te bestuderen. Ze maakten en reeks portretten van de samering dien de de samenteving vallen

Hoewel de gelijkenis tussen dader en toeschouwer mij eerder interessant lijkt als onderzoeksvraag dan als stelling (wordt er geen al te grote gedachtesprong gemaakt van 'de nazi is geen monster' naar 'ieder van ons dragthet kwa de aanleiding voor een soort theater dat zich via een innovatievebeeldtaal eenplatstoe-eigentinde Holocaustcommentair en op een structurele minger Anneleen Spiessens (Universiteit Gent) $\rightarrow$ Meer weten

$\triangle$ De Welwillenden in een bewerking van Guy Cassiers en (Gezien op 13 maart 2016 in Antwerpen.

$\rightarrow$ Bibliografie

$\Leftrightarrow$ Janis Bergman-Carton, "Christian Boltanski's Dernières Années: The history of violence and the violence of history.

istory \& Memory $13(1), 2001,3-18$.

$\Rightarrow$ Christopher Browning, Ordinary Men: Reserve Police HarperCollins, 1992.

Marianne Hirsch, 'Past Lives: Postmemories in Exile', Poetics Today 17(4), 1996, 659-686.

$\diamond$ Erwin Jans, "'Nach Auschwitz ein Gedicht zu Holocaustrepresentatie', persdossier De Welwillenden. Antwerpen: Toneelhuis, 2016

$\diamond$ Jonathan Littell, Les Bienveillantes, Parijs: Gallimard, 2006. H.-., De Welwillenden, vertaald uit het Frans door Jeanne
Holierhoek en Janneke van der Meulen, Amsterdam: De Arbeiderspers, 2008.

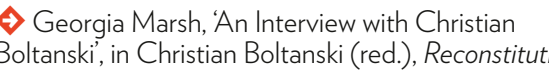
[tentoonstellingscatalogus], Londen: Whitechapel Art Gallery,

$\diamond$ Albert Mingelgrün, 'La figure du bourreau nazi au tournant du XX|' siècle. Quelques variations littéraires', Getuigen 102, 200, 17-27.

$\diamond$ Edwige Perrot \& Guy Cassiers, 'Deconstructie van het 2015, 59-63. Ook beschikbaar als multimediaverhaal op de deconstructie-van-het-verled

$\checkmark$ Anneleen Spiessens, Quand l le bourreau prend la parole; Genève: Droz, 2016

$\rightarrow$ Ernst van Alphen, "Deconstructing the Archive: Visual Archives as

$\diamond$ Harald Welzer \& Michaela Christ, Täter: Wie aus ganz normalen Mensc
S. Fischer, 2006.

\section{Websites}

$\rightarrow$ Invisible Cities, http://invisible-cities

$\diamond$ Test of Civilisation, http://testofcivilisation.eu
(geraadpleegd 30 maart 2016). 